\title{
'The Colorado Sun' Case: A Bet for Digital, Quality, Community and Ethical Journalism
}

\author{
Marçal Sintes-Olivella \\ Ramon Llull University \\ Ester Villacampa-Morales \\ Ramon Llull University \\ Joaquín Marqués-Pascual \\ EAE Business School
}

\begin{abstract}
We are in an era marked by disinformation, fake news and the crisis of journalism that entails an intense crisis of trust. Among the options to escape from this situation, several communication theorists and some companies believe that blockchain technology offers new opportunities for high-quality journalism. Blockchain has its origin in electronic currencies, but it is increasingly being used in digital communication and journalism. This article is dedicated to the case of The Colorado Sun. This study focuses its attention on the following aspects: the mission and objectives of the newspaper at the foot of the Rocky Mountains, its origins and history, the structure and governance system of the media, the function of the cryptocurrency itself and the ethical principles and professional standards that have been awarded. To study the case of The Colorado Sun, in addition to looking at the documents on its website and existing bibliography, we conducted interviews with members of the founding team and different organizations that gave it their support.
\end{abstract}

Keywords: accountability, blockchain, journalism ethics, media, The Colorado Sun

\section{INTRODUCTION: BLOCKCHAIN AND JOURNALISM}

The digital newspaper The Colorado Sun was founded in 2018 by a group of former employees of the printed newspaper The Denver Post. From the first moment, these journalists had the clear idea to work in a digital environment and, at the same time, to integrate their outlet into Civil, the blockchain platform for journalistic media. Today this platform brings together dozens of newsrooms, to which it provides technological support and for which it demands respect for the ethical standards contained in the so-called Civil Constitution.

Blockchain technology is complex. Its story begins on October 31, 2008, when the academic paper titled "Bitcoin: A Peer-to-peer Electronic Cash System", written by Satoshi Nakamoto, was published. In reality, however, this name is an alias, a pseudonym. To this day, no one yet knows Nakamoto's true identity. 
As can be noted from the title of the aforementioned article, blockchain technology was conceived as the basis for the creation of a cryptocurrency or digital currency, the now well-known bitcoin. Bitcoin was the first cryptocurrency, but after it many more have been created using the technology devised by Nakamoto. Since then, the technology has been developed, gaining higher speed and efficiency.

Blockchain is characterized for being an encrypted system that offers practically absolute security, for its network structure, and together with the latter, for not needing any intermediary or third party involved. The system works as a kind of digital notary, making it impossible to retroactively alter or manipulate the content encrypted on the blockchain. Therefore, it ensures the traceability of the saved information blocks and preserves each one of the versions of a document or registered content. This however does not prevent an author or journalist from hiding his or her identity.

From the second half of the last decade, blockchain began to be applied to other areas of activity beyond the creation and circulation of digital currencies. Two examples are the fields of financial transactions and logistics. Likewise, initiatives in the field of communication that tried to take advantage of the features and functions that blockchain offers began to emerge. The first blockchain platform for journalists, Civil, of which The Colorado Sun is a part, was founded in New York in 2017.

The possibilities that the blockchain offers for journalism and communication have been synthesized by various authors.

For example, Walid Al-Saqaf and Malin Picha Edwardson (2019: 100-102) highlight six main areas in which blockchain can be used directly or indirectly for journalism. Namely: 1) Combating fake news and disinformation; 2) Preserving intellectual property; 3) Limiting bias and external influence; 4) Resisting censorship; 5) Protecting whistleblowers, and 6) Encouraging content creation by users. For a more detailed overview of the potential of blockchain in the journalistic sector, see the book by Marqués-Pascual and Sintes-Olivella (2020) Blockchain y periodismo: cómo la cadena de bloques cambiará a los media [Blockchain and Journalism: How blockchain will change the media].

As for the business model, blockchain allows the media to create their own currency and to interact with their readers and advertisers through it. Likewise, the so-called smart contracts can be used in the blockchain environment to remunerate not only the media but also journalists and authors. Consequently, explains Covadonga Fernández, users could "buy, for fractions of euros or bitcoins, articles, video reproductions, news, photos, drawings, subscriptions to the medium by specific pages or sections, reading minutes, hours and days" (Fernández, 2017: 85).

On the other hand, the opportunity that blockchain can offer for advertising has been pointed out by several authors. According to Pepe Cerezo (2018: 38), it can respond to some of the inefficiencies that the advertising market presents today.

Of course, the application of blockchain technology to the field of journalism is not going to solve each one of the challenges and problems that the sector faces, regarding the quality of the contents and the trust of readers, and the traditional business model.

However, it is undeniable that the possibilities that blockchain offers, that may even increase in the future, represent an opportunity for journalism's search for greater proximity to the public and for reform of the traditional business model. In this sense, there are encouraging examples, such as that of The Colorado Sun, as well as a handful of media grouped on the Civil platform or other existing platforms.

\section{HISTORY AND ORIGINS}

The Colorado Sun is a digital native newspaper founded in September 2018 by former employees of The Denver Post in the state of Colorado. The story begins in 2010 when, in the wake of the 2008 global economic crisis, The Denver Post was acquired by the 'vulture' fund Alden Global Capital, which implemented a policy of cuts in several phases. In a period of about eight years, the newspaper's staff was reduced to a fifth of its original volume. Tensions between the new owners and workers escalated when an editorial was published in April 2018 condemning Alden because of its policy. As Stelter (2018) explains, censorship in successive editorials of The Denver Post led to some resignations. 
At the same time, some of these journalists initiated contacts with Civil, the first journalism network based on blockchain technology, with the idea in mind of launching their own project. In June, The Colorado Sun, created by seven reporters and three senior editors from The Denver Post, was announced. It was integrated, along with a dozen other newspapers, into the "first fleet" of newsrooms on Civil. According to Peiser (2018), in this first phase, Civil had one million dollars to finance the said 'fleet' and invested in The Colorado Sun an amount that, although it has not been made public, would allow for its subsistence for two years. This bet is justified, according to Yeste and Xicoy (2019: 107), by the desire for the newspaper to be "a benchmark for other media in a similar economic situation."

However, Civil was not able to keep its pledge. Larry Ryckman, editor of the Colorado Sun, explained the situation to the researchers in a personal interview conducted online on May 2020: "Civil payments to the Colorado Sun were supposed to continue until May 2020 but they stopped back in October 2019 as a result of their crash in cryptocurrency markets and other circumstances. Since then, the Colorado Sun has been operating on its own".

Shortly after this statement, Matthew Iles, Civil CEO, announced the company's shutdown in a blog post: "We built innovative technology, supported award-winning journalists, and inspired many people all over the world with our vision for a more participatory media landscape. But ultimately, we failed to sustain ourselves independently" (Iles, 2020)

Still, Ryckman is very grateful for the help received, not just in cash but also in kind. What he highlights about Civil is its technological support and its lack of editorial influence. "It aims to be a platform, not a publisher," he said in an interview with Medium. Financially, Civil's contribution was complemented by the launch of a crowdfunding campaign through the Kickstarter platform, which by September 2019, had obtained $\$ 161,493$ from 2,622 benefactors, more than double its objective.

\section{MISSION, ORGANIZATION AND VALUES}

The purpose of The Colorado Sun is not limited to finding a way out of the precariousness of journalism, but to offer an alternative to its prevailing model. "The Colorado Sun is not about saving journalists. It's about serving our great state and preserving the extensive institutional memory, journalistic muscle, and passion for storytelling and accountability that we bring to every assignment," wrote Larry Ryckman in his first editorial for the newspaper.

The Colorado Sun model is based on independence and service to the community, therefore the newspaper belongs to journalists (who are equal partners) and is legally constituted as a "public benefit corporation." This formula, which only exists in some areas of the United States, includes those for-profit companies which pursue social good, always acting responsibly and sustainably. This legal model, with no apparent benefits to the company, imposes only two conditions: make an annual report on the community impact of the project and undergo an independent evaluation.

Likewise, The Colorado Sun is characterized by prioritizing quality over quantity and immediacy. "Our mission at The Colorado Sun is to help bring greater understanding to our state through investigative, watchdog, explanatory and long-form narrative journalism that we are delivering online. We are nonpartisan and beholden only to you, our readers. We aim to break news, but not chase daily breaking news that can be quickly forgotten." For this reason, for example, they do not cover sports events.

Consequently, The Colorado Sun's commitment is to develop first-hand content, either by its team of writers or its freelance collaborators - a dozen reporters and photographers -. The Colorado Sun is the first digital media outlet affiliated with the American Society, a national news agency, although it rarely distributes its news. However, the collaboration does work inversely, so some pieces of The Colorado Sun thus have a bigger impact on other media. The collaboration also extends to a dozen newspapers (both print and digital) from the same state with which the medium shares content.

Under the leadership of Ryckman himself the group has been involved in the collaborative project Parked, about the situation of mobile home parks in Colorado. Speaking to the Colorado Media Project, a citizen initiative to promote local and quality journalism in that state, Rychman defends the project in the following way: "Once upon a time news organizations couldn't work together because they viewed each 
other as a threat. In some cases that may still be true, but in many cases it's not. Everyone is so thin and short staffed and just don't have resources they used to."

\section{BUSINESS MODEL}

In addition to its commitment to quality and independent journalism, The Colorado Sun is also an innovator in its business model. The medium rejects paywall and advertising as sources of funding and therefore depends on the support of its community of readers through different types of membership. By May 2020 the newspaper had reached almost 10,000 paying members and 50,000 subscribers to free newsletters. The benefits for paying members, depending on their contribution, range from the reception of premium newsletters to the invitation to events organized by the newsroom, which are another source of funding for the project.

Sponsors, for their part, complement the sources of income of the newspaper in exchange for "advertising" in premium newsletters or the said events. The Colorado Sun also receives money from grants. One of them, from the Wend Ventures educational foundation, permitted the hiring of a reporter specialized in education in November 2018, thus expanding a team that continued to grow in consecutive months until reaching 13 full-time workers in January 2020. However, in the last few months, the newspaper has been forced to adjust its expectations. "Our ambition was to hold equal legs of revenue stool, but Covid-19 has changed everything. The downside of the Coronavirus has been the drop off in sponsorships and events but we have seen better than $15 \%$ growth in our membership since March $1^{\text {st }}$. If we can continue in the aggressive growth path, memberships alone could sustain us somewhere within this year". "We are in a stable financial path", he concludes.

Access to the contents of The Colorado Sun is possible through its website - a mobile application has not yet been enabled. In August 2019, The Colorado Sun had identified 2.7 million unique visits, which are not coming from other websites (The Colorado Sun, 2019). Civil was supposed to remunerate the media that are part of the platform through cryptocurrency, but The Colorado Sun has not directly incorporated on its website any kind of micropayment for journalists or the payment of membership through tokens.

Thus, while in Civil the blockchain had a triple application in terms of content storage, generation of information value and network governance; in the case of The Colorado Sun its use was limited to the storage of just a tiny part of its content. In an interview with The Washington Post in 2018, Ryckman highlights traceability as the blockchain's main asset for the newspaper because it contributes to quality journalism and to restoring readers' trust. "Technology offers the Sun added accountability and transparency... by allowing readers to verify where a story came from and ensure that articles are protected from censorship or deletion." Although he still finds the idea attractive, he sustains that Civil "has never really been able to develop that", so "it became a lower and lower priority" both for Civil and for the Colorado Sun.

\section{ETHICS}

As part of Civil, The Colorado Sun is governed by the so-called Civil Constitution, a document that "in addition to the basic rules of the platform, includes the ethical principles that all its members must respect" (Sintes-Olivella, 2019: 75). That is why it is very unusual for The Colorado Sun to have its own ethics policy, elaborated on in collaboration with the community, who is the guarantor of its fulfilment. The ethics policy consists of ten sections, among which those dedicated to achieving truthfulness, integrity, independence, and accountability stand out.

Although it is very extensive, its basis necessarily coincides with those of the Civil Constitution. The pursuit of truth, for example, necessarily requires impartiality and attention to plurality to adequately distinguish news from opinion. Integrity, for its part, is unattainable when there is a conflict of interest, as well as independence depends at some point on transparency. The ethics policy also includes a chapter dedicated to compassion as the sentiment that should guide the actions of the editorial staff (in the treatment of sources and subjects of analysis, for example). 
The code of ethics is not the only self-regulatory mechanism to which the newspaper is subject, as demonstrated by the aforementioned annual evaluation conducted, in this case, by an external agent. "The law allows us to do the actual measuring ourselves. But we are committed to asking hard questions of ourselves in order to improve as an organization and provide transparency to our readers, so we have done one better. We asked the folks at CU's Media Enterprise Design Lab,...no preconditions attached" (The Colorado Sun, 2019). Institutional transparency is, in fact, one of the newspaper's biggest concerns, as evidenced by the publication on its website of the list of sponsors, premium members, and donors of amounts greater than $\$ 1,000$. However, there are limitations that, according to them, are merely practical.

"Part of demonstrating our independence to the public is being transparent in where our revenue comes from. This assures readers that we have no silent backers and that we aren't a covert plot by a special interest. But it would also be prohibitively burdensome for The Colorado Sun to report the name of every single person who has contributed money, no matter how little and even if their contribution came through the purchase of a standard membership. We also recognize that donors may want to provide contributions anonymously, though we encourage our donors to put their names on their support. We seek to strike a balance, providing as much transparency as is practically possible while also acknowledging that we, like many businesses, just can't disclose everything."

The information on the news elaboration process is also included in the code of ethics, with measures such as the compulsory attribution of texts to their authors and identification of sources (with a few exceptions, always authorized and justified by the editor), or in the news themselves through the credibility indicators devised by Civil and embraced by The Colorado Sun. Along with the aforementioned citation of the sources, are the original and on the ground reporting, and the subject specialist indicators. As Julia Himmel, creative director at Civil, explains, the objectives of these indicators are to provide greater transparency and to gain the trust of the readers. "Writers will be able to select the indicators that apply to their piece, and the selections will be verified by their editors", she stated.

Another known mechanism for accountability in the media, the rectification of incorrect or incomplete

content, is also present in The Colorado Sun's code of ethics. "We never take a lax approach to fixing mistakes". However, specific channels for rectification are not enabled and the responsibility for them falls on the journalists. The collaboration of users, therefore, is not especially visible in the preparation and evaluation of news, since at the moment there is no comment wall enabled and the conversation is redirected to social networks. However, there are several ways for readers to express themselves as well as to send confidential information. "We recently conducted our first reader survey and we heard from more than 2 thousand coloradans, which was more than double what we expected. We regularly meet with members of the public as well to discuss not only our journalism but also our business model", Ryckman explained to us.

\section{REFERENCES}

Al-Saqaf, W., \& Picha Edwardsson, M. (2019). Could blockchain save journalism? An explorative study of blockchain's potential to make journalism a more sustainable business. In R. Massimo \& D. Giuseppe (Eds.), Blockchain and Web 3.0 (pp. 97-113). London: Routledge.

Cerezo, P. (2018). El futuro de la publicidad en la financiación de los medios. Cuadernos para periodistas: Revista de la Asociación de la Prensa de Madrid, 36, 30-39. Retrieved March 11, 2020, from http://www.cuadernosdeperiodistas.com/media/2018/08/Articulo-30-39-PepeCerezo.pdf

Fernández, C. (2017). Medios de comunicación y la blockchain. En A. Preukschat (coord.), Blockchain: La revolución industrial de Internet (pp. 83-88). Barcelona: Gestión 2000.

Gottlieb, A. (2019, October 7). 'Parked' project highlights promise of collaboration. Colorado Media Project. Retrieved May 5, 2020, from https://coloradomediaproject.com/blog/2019/10/7/parkedproject-highlights-promise-of-collaboration 
Himmel, J. (2018, January 4). Media Literacy Starts with Defining Credibility. Blog Join Civil. Retrieved May 7, 2020 from https://blog.joincivil.com/media-literacy-starts-with-defining-credibilityf3a0893543a0

Iles, M. (2020, June 2). Ending of the Civil journey. Civil. Retrieved on June 5, 2020, from https://civil.co/

Marqués-Pascual, J., \& Sintes-Olivella, M. (Eds.). (2000). Blockchain y Periodismo. Cómo la cadena de bloques cambiará a los media. Barcelona: Editorial UOC. ISBN: 978-84-9180-602-8

Nakamoto, S. (2008, October 31). Bitcoin: A Peer-to-Peer Electronic Cash System. Retrieved April 10, 2020, from https://bitcoin.org/en/bitcoin-paper

Peiser, J. (2018, June 17). Goodbye, Denver Post. Hello, Blockchain. The New York Times. Retrieved May 4, 2020, from https://www.nytimes.com/2018/06/17/business/media/denver-postblockchain-colorado-sun.html

Raben, L. (2018, December 17). Q\&A: Larry Ryckman, Editor@ The Colorado Sun. Medium. Retrieved May 6, from https://medium.com/the-idea/q-a-larry-ryckman-editor-the-colorado-sun$5362 \mathrm{fc} 798 \mathrm{ad} 6$

Rychman, L. (2018, September 10). A welcome letter from our editor. The Colorado Sun. Retrieved May 7, 2020, from https://coloradosun.com/2018/09/10/larry-ryckman-welcome-letter/

Shaban, H. (2018, June 20). How veteran journalists in Colorado are using the blockchain to build a news start-up. The Washington Post. Retrieved May 6, from

https://www.washingtonpost.com/news/the-switch/wp/2018/06/20/how-veteran-journalists-incolorado-are-using-the-blockchain-to-build-a-news-start-up/

Sintes-Olivella, M. (2020). Calidad periodística, confianza y blockchain. In J. Marqués-Pascual \& M. Sintes Olivella (Eds.), Blockchain y periodismo. Cómo la cadena de bloques cambiará los media (pp. 58-78). Barcelona: Editorial UOC.

Stelter, B. (2018, Mat 7). Denver Post staffers protest 'censorship' of editor who criticized owner. CNN Money. Retrieved May 4, 2020, from https://money.cnn.com/2018/05/07/media/denver-postrebellion/index.html

The Colorado Sun. (2019). Annual Report. Retrieved May 7, 2020, from https://coloradosun.com/annualreport/

Yeste Piquer, E., \& Xicoy i Comas, E. (2020). Civil y Popula. Ejemplo de periodismo con Blockchain. In J. Marqués-Pascual \& M. Sintes Olivella, (Eds.), Blockchain y periodismo. Cómo la cadena de bloques cambiará los media (pp. 96-118) Barcelona: Editorial UOC. 